\title{
Entrepreneurial Framework Conditions and Impact Scores of Small-Size Certified Benefit Corporations (CBCs). A Configurational Analysis of 17 Countries
}

\author{
Alberto Ruozzi ${ }^{1}$ and Jose Antonio Vicente ${ }^{2, *}$ \\ 1 Business Organization and Marketing Department, Complutense University of Madrid, 28223 Madrid, Spain; \\ aruozzi@ucm.es \\ 2 Market Research and Quantitative Methods Department, ESIC Business and Marketing School, \\ 28223 Madrid, Spain \\ * Correspondence: joseantonio.vicentepascual@esic.edu
}

check for updates

Citation: Ruozzi, A.; Vicente, J.A. Entrepreneurial Framework Conditions and Impact Scores of Small-Size Certified Benefit Corporations (CBCs). A

Configurational Analysis of 17 Countries. Sustainability 2021, 13 , 7297. https://doi.org/10.3390/ su13137297

Academic Editors: Olimpia Meglio and Nadia Di Paola

Received: 30 April 2021

Accepted: 26 June 2021

Published: 29 June 2021

Publisher's Note: MDPI stays neutral with regard to jurisdictional claims in published maps and institutional affiliations.

Copyright: (c) 2021 by the authors. Licensee MDPI, Basel, Switzerland. This article is an open access article distributed under the terms and conditions of the Creative Commons Attribution (CC BY) license (https:/ / creativecommons.org/licenses/by/ $4.0 /)$.

\begin{abstract}
The urgent need that the private sector generate positive social and environmental impacts in order to cope with the grand challenges faced by humanity and contribute to sustainable development, has ignited the need to understand the country conditions that could promote such an endeavor, especially for small firms who may have more difficulties and, among them, those that try to generate positive impacts for multiple stakeholders, such as Certified B Corporations (CBCs). To contribute to such understanding, we use fsQCA to identify the combinations of presence/absence of four entrepreneurial framework conditions (EFCs) - financing for entrepreneurs, taxes and bureaucracy, R\&D transfer, and commercial and legal infrastructure-that are sufficient for the presence/absence of a high average impact score of small-size CBCs in the country. The analysis reveals that two combinations of the presence/absence of the considered EFCs are sufficient for the presence and another two are sufficient for the absence of that outcome. General patterns, specific combinations and the implications for policymakers, CBCs managers and future research are discussed.
\end{abstract}

Keywords: entrepreneurial framework conditions; impact; certified B corporations; small firms; sustainable entrepreneurship

\section{Introduction}

There is an increasing need of private sector contributions in the form of positive impact generations to face the grand challenges faced by humanity [1], achieve the Sustainable Development Goals [2] and cope with the negative impacts of the actual COVID-19 crisis [3,4].

This has led firms to face increasing pressure from multiple stakeholders to behave in a more sustainable and socially responsible way [5,6], which, in turn, has ignited the interest of academics, managers, policymakers and other relevant stakeholders in the phenomenon of sustainable entrepreneurship, in general, and that of the B Corporations and the Certified B Corporations (CBCs hereon), in particular. This interest results from the fact that the organizations within those realms simultaneously pursue market and social logics in order to generate positive impacts at the social and environmental level for multiple stakeholders [7].

Nonetheless, whereas states need the contributions of firms, firms also need institutional support, especially those that, apart from pursuing social and environmental goals, are also small and/or young. In fact, it has been noted that it is relevant to consider the contributions of SMEs to sustainable development given that they represent nearly $95 \%$ of global employment [6].

Even more, the majority of small firms and entrepreneurs generally do not possess the necessary resources to cope with the grand challenges, which, in conjunction with 
the absence of additional supports by government actors, may discourage them from contributing to their resolution [8].

This has led to an increasing interest in the reasons behind country differences in entrepreneurial activities and outcomes [9]. It has been found that the presence or absence of institutional conditions may generate complementarities (either facilitative or restrictive) that conjointly lead to differences in them across countries $[10,11]$. This has also been found regarding the generation of positive non-financial impacts of entrepreneurs in big samples with firms of various sizes and from multiple sectors [12].

Nonetheless, the majority of previous studies looking at the relationship between entrepreneurial framework conditions (institutions specifically relevant for entrepreneurship; EFCs hereon) and entrepreneurial activities and outcomes, mainly analyzed one by one relationships or moderation/mediation ones (e.g., $[9,11])$. Additionally, with the aim of providing a solid foundation for future research and increasing our general understanding, those studies have generally aggregated the EFCs in the three major dimensions of institutional conditions: regulatory, cultural-cognitive and normative. However, of course, given the natural limitations of any study in terms of its scope [13], they have not focused on specific institutional conditions that may be relevant on their own.

Subsequently, it has been asked to complement those works by analyzing the conjoint influence of those specific EFCs [10], especially given the still scarce understanding of how institutional conditions interact in order to produce different outcomes $[10,14]$ and the need of more studies regarding how institutional systems interact in order to influence the corporate social performance (a concept that overlaps with that of impact) of firms [15].

Therefore, in order to approach this gap and contribute to our understanding of how EFCs may promote (or hinder) the average impact generated by small-size CBCs, we focus on four EFCs, whose presence (absence) promote (do not promote) SMEs, and that we consider relevant for achieving (or not) that outcome: financing for entrepreneurs, taxes and bureaucracy, R\&D transfer and commercial and legal infrastructures. By focusing on them, we answer the following research question: $i$ what are the combinations of presence/absence of the considered EFCs that are sufficient for the presence/absence of a high average impact score of small-size CBCs in the country?

It must be noted that, given the absence of studies like that, in conjunction with the scarce literature regarding CBCs and configurational analyses of EFCs, this study is exploratory in nature. Therefore, it does not focus on testing a specific hypothesis (which is adequate for confirmatory studies), but in identifying the aforementioned combinations with the aim to explain their coherence and suggest future research avenues that deepen our understanding regarding them and their outcomes, and by testing more concrete causal mechanisms surrounding them.

In particular, those combinations are found using the fuzzy-set Qualitative Comparative Analysis method [16] with 2019 data from 17 countries. For EFCs, we use data from the Global Entrepreneurship Monitor, and for impact generation, we aggregate for each country the sum of impacts of small-size CBCs (1 to 9 and 10 to 49 employees), obtained from the B Corp data.

By identifying those combinations of specific EFCs sufficient for the presence/absence of a high average impact score of small-size CBCs in a country, we contribute to the growing research stream interested in understanding how institutional conditions influence them and their differences across countries [e.g., 9,10,11], and specifically to those works focusing on their influence on the positive impact generation of firms (e.g., [3,15]).

Those findings also contribute to the scarce but growing stream of research on the impact generation of CBCs (e.g., $[17,18])$ and the ways in which institutional factors may promote or hinder it (e.g., [3], complementing those works by focusing on a small set of countries, on small-size CBCs and on specific EFCs.

In particular, our results reveal two combinations of presence and absence of the considered EFCs for both the presence and the absence of a high average impact score of small-size CBCs in the countries. These major findings point to the crucial necessity that 
policymakers consider the complementarities between EFCs and their potential influence on the impact generation of firms in a holistic way. We discuss the implications of those findings for policymakers, CBCs managers and future research.

The rest of the article is structured as follows: In Section 2, we develop our theoretical framework in order to expose the relevance and characteristics of our variables of interest. The Section 3 covers the methodology. The Section 4 shows the results, and in the Section 5, we discuss them and conclude the article.

\section{Theoretical Framework}

\subsection{Context of Analysis and Outcome of Interest: Certified B Corporations (CBCs) and Their Generation of Positive Impacts}

2.1.1. The Emergence of CBCs. Main Characteristics and Relationship with Sustainable Entrepreneurship

The B Corp phenomenon and the birth of CBCs have their origins in the American NGO B Lab, which is rapidly growing at a global level with two objectives in mind: (a) build a strong community of CBCs around the world [19]; (b) help entrepreneurs to measure, communicate and legitimatize their benefits in markets, as well as their generation of positive impacts at the social, environmental and/or governance level [5].

In order to become a CBC, firms must accept and complete an audit process performed by $\mathrm{B}$ Lab, who constitute an external party that evaluate firms regarding their activities and commitment in their values, mission and governance systems directed to generate positive impacts in five dimensions (pillars, in B Corp terms): communities, workers, customers, governance and the environment.

In order to opt for certification, firms must first complete, by themselves, a questionnaire (B Impact Assessment) that considers various activities and policies directed toward the generation of positive effects in the aforementioned dimensions. They may be considered valid for becoming a B Corp, only if they obtain a minimum score of 80 points from a maximum of 200. Once this is complete, external auditors from B Lab go to the firms and evaluate if they have really implemented what they describe in the questionnaire, suggesting changes when needed [20], and if such implementation is paired with an alignment of financial and social and/or environmental missions [5]. Additionally, firms desiring to maintain their certification must undergo the certification process every three years; every year B Lab randomly audit $10 \%$ of the CBC population [18].

It must be noted that this process may raise suspicion (e.g., greenwashing) to external agents given the fact that the certification is obtained from B Lab and starts from an auto-evaluation process. This may lead someone to think that, in the end, B Lab is going to certify every interested company in order to increase their global presence and the income resulting from the annual costs of the certification. Nonetheless, it seems not to be the case given the evidence that all the firms undergoing the certification process had to make significant changes in their practices and policies, which, in many cases, implied considerable change [7].

In that sense it has been stated that, although we do not know if the B Corps and CBCs are the ideal organizational category for private firms' contribution to sustainable development and big challenges, it can actually be said that they can represent a significant step in the transition toward more sustainable paradigms [5].

Subsequently, the certification reflects that the firm is committed in terms of values, mission, policies and activities, with a business model that aims to create economic, social and/or environmental value, through the realization of activities that pursue ethical and sustainable goals [21]. In particular, this is the main distinction between small-size CBCs and the general population of SMEs, which, in some cases, may also have similar goals reflected through their Corporate Social Responsibility, other kinds of certifications (e.g., ISO rules for environmental management quality) or, simply, in their nature, as is the case of sustainable firms common to the field of sustainable entrepreneurship. 
Nonetheless, in the case of $\mathrm{CBC}$, such a commitment is explicitly communicated and manifested in the aforementioned alignment of the mission, values, policies and practices within it, and if it has been certified by external agents (e.g., B Lab auditors).

Given the above, in the following sub-sections, we expose both the particular kind of positive impacts generated by $C B C$ s, as well as the struggles they face in order to generate them as a consequence of their particular nature, as stated above.

\subsubsection{Impact Generation of CBCs}

CBCs generate a multidimensional impact that consider the demands of multiple stakeholders $[18,19]$. This is a consequence of the incorporation of a social purpose in the firm's mission and activities with the aim of generating positive impacts [3], which, as stated above, is their main difference with the general for-profit firms' population (i.e., SMEs).

In particular, the kind of issues that are evaluated in each of the impact dimensions (governance, communities, workers, customers and environment) are those indicated in Table 1, with the role of B Lab being that of measuring and evaluating their deployment in the firms interested in the certification or trying to renew it and giving them proper feedback in order to improve across them [20]. In particular, the global impact score that may go from 80 to a maximum of 200 , as mentioned above, results from the sum of the particular actions in each of the pillars.

Table 1. B Corp impact pillars.

\begin{tabular}{|c|c|}
\hline Impact Pillar & B Impact Assessment Description \\
\hline Community & $\begin{array}{l}\text { "Evaluates a company's supplier relations, diversity, and involvement in the local community. It also measures } \\
\text { the company's practices and policies around community service and charitable giving, including whether a } \\
\text { company's product or service is designed to solve a social issue, such as access to basic services, health, } \\
\text { education, economic opportunity and the arts." }\end{array}$ \\
\hline Workers & $\begin{array}{l}\text { "Assesses the company's relationship with its workforce. It measures how the company treats its workers } \\
\text { through compensation, benefits, training and ownership opportunities provided to workers. The category also } \\
\text { focuses on the overall work environment within the company by assessing management/worker } \\
\text { communication, job flexibility, corporate culture, and worker health and safety practices." }\end{array}$ \\
\hline Customers & $\begin{array}{l}\text { "Measures the impact a company has on its customers by focusing on whether a company sells products or } \\
\text { services that promote public benefit and if those products/services are targeted toward serving underserved } \\
\text { populations. The section also measures whether a company's product or service is designed to solve a social or } \\
\text { environmental issue (improving health, preserving environment, creating economic opportunity for } \\
\text { individuals or communities, promoting the arts/sciences, or increasing the flow of capital to } \\
\text { purpose-driven enterprises)." }\end{array}$ \\
\hline Environment & $\begin{array}{l}\text { "Evaluates a company's environmental performance through its facilities, materials, emissions, and resource } \\
\text { and energy use. Companies answer questions about their transportation/distribution channels and the } \\
\text { environmental impact of their supply chain. The assessment also measures whether a company's products or } \\
\text { services are designed to solve an environmental issue, including products that aid in the provision of } \\
\text { renewable energy, conserve resources, reduce waste, promote land/wildlife conservation, prevent } \\
\text { toxic/hazardous substance or pollution, or educate, measure or consult to solve environmental problems." }\end{array}$ \\
\hline Governance & $\begin{array}{l}\text { "Evaluates a company's overall mission, ethics, accountability and transparency. It measures whether the } \\
\text { company has adopted a social or environmental mission, and how it engages its employees, board members } \\
\text { and the community to achieve that mission. This section assesses employee access to financial information, } \\
\text { customers' opportunities to provide feedback, and the diversity of the company's governing bodies." }\end{array}$ \\
\hline
\end{tabular}

Source: "Complete guide to the B Corp Certification for Small-Medium Sized Enterprises" accessed on 31 May 2021 at shorturl.at/sEIY2.

Regarding the specific way of generating positive impacts across the dimensions highlighted in Table 1, CBCs consider benefits as means to an end-their social and/or environmental mission-giving them relevance in terms of how they contribute to the achievement of their social purpose [7] and focusing on specific practices that create social or environmental value in a similar way to that of social enterprises [20]. For example, they consider local actors in their governance processes in order to jointly manage institutional demands and co-create positive impacts [22] or, more generally, they offer products and services that are generating a positive impact from the moment they are sold (e.g., education 
about sexuality in underdeveloped regions of the world, destination of benefits to the alleviation of poverty).

It must be noted that in our study we are not focusing on the specific level of impact of CBCs at the firm level, instead we are interested in understanding if relevant EFCs can help (when present) or impede (where absent) so that the average impact generated by small-size CBCs is high. Given that, in the following sub-section, we highlight the particular struggles they face and that may be alleviated by the presence of the studied EFCs, some of them being common to SMEs, whereas others specifically result from their particular nature and the dual mission CBCs pursue.

\subsubsection{Struggles Faced by CBCs}

The hybrid nature of $\mathrm{CBC}$ s and the fact that, in many cases, they are small and/or young firms, creates various hindrances that they must face through the certification and impact generation processes.

Generally, although the mutual pursuit of economic, social and environmental goals may lead to synergistic effects, it also implies trade-offs resulting in complexities and ambiguities that result from the mutual presence of market and social logics guiding sustainable entrepreneur activities [23].

In particular, CBCs, especially smaller and/or younger ones, may have difficulties in this endeavor as a consequence of the lack of economic resources, business knowledge and/or external environment support [24].

Therefore, in order to achieve their goals, $\mathrm{CBC}$ s have to overcome the implicit tradeoffs of simultaneously pursuing market and societal logics [7], while adapting to the external environment and attending the demands of multiple stakeholders. Nonetheless, this can be particularly difficult for small and/or young firms, especially regarding social impacts which, compared with environmental ones, are more difficult to measure, leading, in many cases, to difficulties for CBCs when trying to comply to B Lab standards [5].

\subsection{Specific Entrepreneurial Framework Conditions Relevant for Promoting Small-Size CBCs} Impact Generation

2.2.1. Heterogeneity of Entrepreneurial Framework Conditions and Its Associated Outcomes. Institutional Theory and Varieties of Capitalism Perspectives

Institutional theory [25] has been widely used for explaining differences in entrepreneurial activities and outcomes across multiple contexts [11], with institutions being defined as a "set of rules that articulates and organizes the economic, social and political interactions between individuals and social groups, with consequences for business activity and economic development" [9] (p. 705). The relevance of institutions stems from the fact that they constitute social structures with high resiliency and with the role of providing significance and stability to social interactions [26], therefore influencing human behavior [27].

In the case of social entrepreneurs and firms such as $\mathrm{CBC}$, the relevance of institutions is magnified because of the higher number of norms and restrictions they have to face as a consequence of institutional contexts' dynamism and the multidimensionality of the impact they try to generate [20].

Of particular interest for this study is the argument that one of the main reasons for which institutional conditions can positively influence entrepreneurship activities and outcomes, is because they emerge in order to mitigate the costs associated with the negotiation, monitorization and enforcement of exchange processes [28]. This helps to understand why firms in countries with better EFCs may be advantaged with respect to those in countries with worse ones.

This argument is coherent with the Varieties of Capitalism (VOC) perspective [29]. It posits that there are different types of economies composed that characterize groups of countries with similar institutional trajectories, therefore pointing to the potential existence of comparative advantages/disadvantages across countries, depending on the institutional conditions of the countries in which they operate [30] and highlighting the idea that there are multiple possible pathways for becoming a rich/poor economy [31]. 
Applied to the field of entrepreneurship, the goal of this perspective is that of explaining how differences in institutional conditions (i.e., EFCs) between countries lead to different institutional contexts that are associated with different entrepreneurial behaviors and outcomes [32].

Given the above, in this study, the aim is that of identifying the combinations of the presence/absence of four EFCs we consider relevant in terms of helping (when present) or hindering (when absent) when the average impact score of small-size CBCs is high, therefore contributing to the overall level of impact they generate at the national level. The presence/absence of such high average impact scores of small-size CBCs in the country is the outcome of interest in this study. In particular, the selected EFCs are: (a) entrepreneurial finance, (b) taxes and bureaucracy, (c) R\&D transfer and (d) commercial and legal infrastructures. The definitions according to the GEM are indicated in Table 2.

Table 2. Analyzed entrepreneurial framework conditions.

\begin{tabular}{cr}
\hline Entrepreneurial Framework Conditions & Global Entrepreneurship Monitor Definition \\
\hline Financing for entrepreneurs & $\begin{array}{c}\text { The availability of financial resources-equity and debt-for small and medium } \\
\text { enterprises (SMEs) (including grants and subsidies). }\end{array}$ \\
\hline Government policies: taxes and bureaucracy & $\begin{array}{c}\text { The extent to which public policies support entrepreneurship—taxes or } \\
\text { regulations are either size-neutral or encourage new and SMEs. }\end{array}$ \\
\hline R\&D transfer & $\begin{array}{r}\text { The extent to which national research and development will lead to new } \\
\text { commercial opportunities and is available to SMEs. }\end{array}$ \\
\hline Commercial and legal infrastructures & $\begin{array}{c}\text { The presence of property rights, commercial, accounting and other legal and } \\
\text { assessment services and institutions that support or promote SMEs. }\end{array}$ \\
\hline
\end{tabular}

Source: https:/ / www.gemconsortium.org/wiki/1154 (accessed on 20 April 2021).

In a general sense, the EFCs represent the set of institutions that reflect the political interests toward entrepreneurship in an ample sense [33].

Regarding their relevance, it has been found that the EFCs that most positively influence the economy and entrepreneurs are those that constitute channels for the interaction of enterprises, investors, the labor markets and R\&D partners, because through those channels, firms have more opportunities for building competitive advantages [32].

Considering the above, we argue that the four ECF chosen meet the previous conceptualization and, in themselves, constitute valuable mechanisms through which policymakers may try to promote, not only entrepreneurship, but also the generation of positive nonfinancial impacts by entrepreneurs and SMEs, such as CBCs.

\subsubsection{Entrepreneurial Finance}

One of the biggest barriers of small enterprises is the access to financial resources, which, in the case of CBCs, has been found to be a reason why they opt for de-certification [5] as a consequence of the deviation from their social and environmental goals, because of financing difficulties and barriers for obtaining resources [7].

In fact, it has been stated that financing is a critical tool for entrepreneurs [33] which, in the case of $\mathrm{CBCs}$, may be particularly true, given the evidence that external threats and high financial pressures can lead them to deviate from their social and/or environmental mission [7].

One reason for those struggles is that the absence or weakness of credit and equity markets create significant difficulties for entrepreneurs when they try to obtain external financing because it leads to the persistence of agency costs and information asymmetries [28].

This problem may be further aggravated by the fact that many CBCs see profits as means to an end, leading them to reduce their margins, at minimum, in order to simply ensure survival and to keep creating social and environmental value by selling their products and/or services. This means that in situations of difficulties, small CBCs may experience considerable tensions and struggles given their low capital and the inherent trade-offs of their business models. 
Given the above, we argue that the presence/absence of support for SMEs in the form of entrepreneurial finance is a relevant EFC that may promote/hinder the generation of positive impacts of small-size firms such as $\mathrm{CBCs}$ and, therefore, can promote/hinder the presence/absence of a high level of their total impact generation at the national level in comparison with other countries.

\subsubsection{Government Policies: Taxes and Bureaucracy}

The existence of taxes that try to achieve equality instead of equity between enterprises may suppose a disadvantage for small and/or young firms given their reduced capacity, with respect to medium and big ones in terms of generating benefits and accessing resources, whereas an excessive bureaucracy may be particularly problematic in the initial phases of a company [34] cf. [9].

Subsequently, both taxes and bureaucracy have been identified as potential barriers for entrepreneurs [9], which has led to suggest the reduction of required costs and licenses and the implementation of more favorable fiscal systems as useful mechanisms for reducing entry- as well as growth-barriers faced by entrepreneurs [35] cf. [9].

In the case of $\mathrm{CBCs}$, we argue that reducing bureaucracy complexity and requirements could be particularly valuable for small-size CBCs, given that they imply more administrative work that may make the pursuit of their dual mission difficult and exacerbate the difficulties they experience as a consequence of attending to multiple stakeholders' demands while trying to generate positive impacts, as well as benefits necessary for survival.

Additionally, fiscal help could be highly beneficial for CBCs given that many of them achieve their impacts directly through the selling of their products [24], which many times leads them to reduce their margins in order to make their offer more accessible [5].

Nonetheless, promoting this requires that entrepreneurs and SMEs are supported in the pursuit of their social purpose given the evidence that the existence of inefficient and unpredictable taxes [10] and an excessive bureaucracy may impede them to achieve it.

Subsequently, given the potential of bureaucracy and fiscal systems for increasing (or reducing) the risks and benefits of entrepreneurs [11], we argue that this EFC is relevant for promoting/hindering a high average impact score of small-size CBCs in the country.

\subsubsection{R\&D Transfer}

One of the main ways through which sustainable entrepreneurs can achieve competitive advantages and generate positive impacts, is realizing and implementing innovationsespecially radical ones-in their business model, processes and the products and services they offer, that allow them to contribute to the benefit of society and/or the environment.

This is particularly related to R\&D transfer given the evidence that technological advances and scientific discoveries that lead to the aforementioned innovations are related with development of pro-social actions with relevant implications for society and/or the environment [12]. In short, scientific and technological research provides the basis for the knowledge that leads to technological innovations and their commercialization [11].

It must be noted that the aforementioned knowledge is generally costly to obtain [11], especially for small firms that, in many cases, do not have the financial resources to access recent technological and scientific developments and discoveries, leading them to collaborate with firms and research centers in order to obtain it in a cheaper and efficient way [32].

In synthesis, the level of R\&D transfer toward new firms and SMEs allows smallsize CBCs to access the most updated knowledge that they may need, not only to realize sustainable innovations that can lead to the generation of positive impacts, but also to keep their competitive position with respect to other firms that possess more resources to access or even create it. Therefore, we argue that it is an EFC whose presence/absence can promote/hinder the presence/absence of a high average impact score of small-size CBCs in the country. 


\subsubsection{Commercial and Legal Infrastructures}

The presence of commercial infrastructures is a critical factor for facilitating entrepreneurial activities and outcomes [36]. One of the most common ways for small firms to survive and prosper is forming alliances with other organizations in order to learn and co-create innovations and a differentiated offer that will allow them to stay in the market.

This can be particularly relevant for CBCs given that their business model implies an exhaustive consideration of the demands of multiple stakeholders that may be particularly difficult to attend to for smaller and younger firms, leading them to establish the aforementioned alliances.

Subsequently, the legal infrastructure that governs the relationships between organizations, is also critically relevant for firms in general, but especially for small and/or young firms, because a misunderstanding of those rules may lead them to be reluctant toward establishing the aforementioned alliances. This could further lead them to lose a potential opportunity for learning and co-creating competitive advantages that could help them to survive and strive in the market while accomplishing their social purpose.

In synthesis, given that the presence of legal and commercial infrastructures can help new and SMEs to avoid the transaction costs related with the ignorance of legal factors and reduce the risks associated with possible non-compliance in organizational alliances, we argue that this is a relevant EFC for promoting (or hindering) the presence of a high average impact score of small-size CBCs in the country.

With all the above, we have pointed to the relevance of the considered EFC showing how their presence may constitute a driver for impact generation, whereas their absence can be a barrier. In that sense, we argue that the real relevance of such effects can be seen by looking at those EFCs together, thus being able to identify specific drivers or barriers resulting from their complementarities (synergistic or antagonistic depending on the presence/absence of EFCs). Given that, in the next section, we expose how we use fsQCA in order to identify the combinations of presence/absence of those EFCs that are sufficient for the presence/absence of a high average impact score of small-size CBCs in the analyzed countries.

\section{Methodology}

\subsection{Sample and Measures}

In order to obtain the data necessary for answering our research question, we combined two databases: the Global Entrepreneurship Monitor (GEM) and the B Corp one, both publicly available (Global Entrepreneurship Monitor data can be obtained at https: / / www.gemconsortium.org/data (accessed on 25 January 2021), whereas the most recent version of the B Corp database can be obtained at https:/ / data.world/blab/b-corp-impact-data (accessed on 25 January 2021)). In particular, we wanted to use the most recent data in order to obtain the most updated results possible. Therefore, we took data from the 2019 year from both databases given that 2020 data was not available for the GEM database.

This decision led us to a final sample of 17 countries for which we had available data regarding the analyzed EFCs, as well as data regarding small-size CBCs (1 to 9 and 10 to 49 employees). In particular, we think that both databases were adequate for the purpose of this study, which is that of identifying the combinations of presence/absence of the considered EFCs that are sufficient for the presence/absence of a high impact score (with respect to the other analyzed countries) at the national level.

In that sense, the GEM database has been widely used for studying the relationships of EFCs with various entrepreneurial activities and outcomes (e.g., [9-11]), whereas the B Corp database is the only one (logically) which provides data regarding impact scores of CBCs, including certified and de-certified firms, focusing on the former in our study.

In order to obtain our measures of interest regarding impact at the national level, we used the average impact scores (can range from a minimum of 80 to a maximum of 200, according to the BIA) of the small-size CBCs, with 1 to 9 and with 10 to 49 employees, 
and used the average of those two scores as the average impact score of small-size CBCs in the country. Regarding EFCs (can range from a minimum of 0 to a maximum of 5 according to the GEM), we simply used the 2019 score of the 17 analyzed countries. All the aforementioned measurements are shown in Table 3.

Table 3. Small-size CBCs, average impact scores and EFCs scores by country.

\begin{tabular}{|c|c|c|c|c|c|c|c|c|c|c|}
\hline \multirow[b]{2}{*}{ Country } & \multicolumn{2}{|c|}{$\begin{array}{l}\text { CBCs (1-9 } \\
\text { Employees) }\end{array}$} & \multicolumn{2}{|c|}{$\begin{array}{l}\text { CBCs (10-49 } \\
\text { Employees) }\end{array}$} & \multicolumn{2}{|c|}{ Overall Country } & \multicolumn{4}{|c|}{$\begin{array}{c}\text { Entrepreneurial Framework } \\
\text { Conditions }\end{array}$} \\
\hline & $\begin{array}{l}\text { Number } \\
\text { of Firms }\end{array}$ & $\begin{array}{c}\text { Average } \\
\text { Impact } \\
\text { Score }\end{array}$ & $\begin{array}{l}\text { Number } \\
\text { of Firms }\end{array}$ & $\begin{array}{c}\text { Average } \\
\text { Impact } \\
\text { Score }\end{array}$ & $\begin{array}{l}\text { Number } \\
\text { of Firms }\end{array}$ & $\begin{array}{c}\text { Average } \\
\text { Impact } \\
\text { Score }\end{array}$ & FIN & TAX & TRA & INF \\
\hline Australia & 94 & 89.76 & 95 & 89.18 & 189 & 89.47 & 3.10 & 2.70 & 2.52 & 3.09 \\
\hline Brazil & 44 & 97.91 & 55 & 93.78 & 99 & 95.62 & 2.93 & 1.87 & 2.25 & 2.82 \\
\hline Canada & 118 & 95.37 & 91 & 95.41 & 209 & 95.39 & 3.16 & 2.76 & 2.66 & 3.22 \\
\hline Chile & 45 & 92.04 & 38 & 93.32 & 83 & 92.62 & 2.42 & 2.85 & 2.41 & 2.70 \\
\hline Colombia & 19 & 90.03 & 18 & 98.62 & 37 & 94.21 & 2.23 & 2.16 & 2.35 & 2.52 \\
\hline Germany & 14 & 91.66 & 15 & 98.17 & 29 & 95.03 & 3.13 & 2.64 & 2.89 & 3.59 \\
\hline India & 1 & 91.90 & 2 & 102.95 & 3 & 99.27 & 3.37 & 3.05 & 3.15 & 3.34 \\
\hline Italy & 39 & 90.78 & 44 & 91.70 & 83 & 91.27 & 2.80 & 2.18 & 2.90 & 2.98 \\
\hline Netherlands & 34 & 92.69 & 35 & 89.88 & 69 & 91.27 & 3.64 & 3.25 & 3.22 & 3.58 \\
\hline South Korea & 6 & 90.48 & 5 & 92.30 & 11 & 91.31 & 2.92 & 1.85 & 2.43 & 3.02 \\
\hline Spain & 6 & 90.38 & 8 & 91.86 & 14 & 91.23 & 3.02 & 2.81 & 2.63 & 2.73 \\
\hline Sweden & 24 & 95.43 & 14 & 90.52 & 38 & 93.62 & 3.00 & 3.10 & 3.24 & 3.58 \\
\hline Switzerland & 2 & 82.20 & 1 & 80.40 & 3 & 81.60 & 3.07 & 2.37 & 2.66 & 3.13 \\
\hline Taiwan & 16 & 90.46 & 13 & 90.35 & 29 & 90.41 & 3.24 & 3.51 & 3.58 & 3.57 \\
\hline United Kingdom & 9 & 93.46 & 11 & 92.82 & 20 & 93.11 & 3.27 & 3.20 & 3.19 & 3.34 \\
\hline United States & 130 & 92.22 & 126 & 91.10 & 256 & 91.67 & 3.13 & 3.05 & 2.42 & 3.01 \\
\hline
\end{tabular}

Source: made by authors. Note: FIN indicate "financing for entrepreneurs"; TAX indicate "taxes and bureaucracy"; TRA indicate "R\&D transfer"; INF indicate "commercial and legal infrastructures".

\subsection{Method of Analysis: Fuzzy-Set Qualitative Comparative Analysis ( $f_{s} Q C A$ )}

Given that our aim is to identify the combinations of presence/absence of EFCs sufficient for the presence/absence of a high average impact score of small-size CBCs in the country, we used fsQCA since this method is specifically suited to finding these types of results.

In particular, according to Ragin $[16,37,38]$, the three main characteristics that differentiate fsQCA from other quantitative (e.g., statistical) and qualitative (e.g., case studies) methods are: (a) instead of identifying correlations between variables, the goal is to identify the variables (i.e., EFCs) (termed causal conditions) and the combinations of them (termed configurations) sufficient for the presence or absence of a specific outcome (i.e., high impact at the national level); (b) fsQCA is originally designed for studying medium-size samples but is also well suited for analyzing smaller (between 15-20 cases) [12] and bigger ones (see [39]; (c) as fsQCA allows for establishing the existence of multiple causality or equifinality, that is, that the outcome of interest may be achieved (or not) through different configurations of the presence or absence of the causal conditions.

In order to perform the fsQCA analysis, it was necessary that cases (i.e., countries) were classified according to the degree of presence of the causal conditions (i.e., EFCs) and the outcome (high impact at the national level) in them. This process is called calibration and required the establishment of a rule in order to give scores to each case according to the degree of focus on each EFC, and the degree of overall impact generated by small-size CBCs. According to Ragin (2008) [38], the process of calibration requires the definition of three thresholds: (a) fully in (high level of the condition or outcome); (b) fully out (low level of the condition or outcome); and (c) crossover or maximum ambiguity point (neither high or low level of the condition or outcome).

In order to choose the precise values for those threshold points, we followed previous articles analyzing EFCs with fsQCA in high impact journals (e.g., [10]) and established the 
fully in threshold at the 95th percentile, the fully out threshold at the 5th percentile and the crossover point at the 50th percentile. Specifically, Table 4 shows the results from the calibration, as well as main statistics for the average impact score of small-size CBCs in a country (OVE in the Table 5) and the EFCs.

Table 4. Calibration cut-offs.

\begin{tabular}{cccccccc}
\hline & \multicolumn{3}{c}{ Calibration Thresholds } & \multicolumn{3}{c}{ Descriptive Statistics of the Sample } \\
\cline { 2 - 8 } Condition & Fully Inside & Maximum Ambiguity & Fully Outside & Max & Min & Mean & Standard Deviation \\
\hline OVE & 96.90 & 92.62 & 87.89 & 99.27 & 81.60 & 92.45 & 3.69 \\
FIN & 3.53 & 3.10 & 2.38 & 3.64 & 2.23 & 3.05 & 0.35 \\
TAX & 3.34 & 2.81 & 1.87 & 3.51 & 1.85 & 2.73 & 0.49 \\
TRA & 3.36 & 2.66 & 2.33 & 3.58 & 2.25 & 2.78 & 0.38 \\
INF & 3.58 & 3.13 & 2.66 & 3.59 & 2.52 & 3.15 & 0.34 \\
\hline
\end{tabular}

Source: made by authors.

Table 5. Analysis of sufficient conditions: presence (Model 1) and absence (Model 2). Complex solution.

\begin{tabular}{|c|c|c|c|c|}
\hline \multirow[b]{2}{*}{ Condition } & \multicolumn{2}{|c|}{ Model 1. Presence of High Level of Impact. } & \multicolumn{2}{|c|}{ Model 2. Absence of High Level of Impact. } \\
\hline & 1a & $1 \mathrm{~b}$ & $2 a$ & $2 b$ \\
\hline FIN_RD & • & o & & ० \\
\hline TAX_RD & $\circ$ & $\bullet$ & $\bullet$ & $\circ$ \\
\hline TRA_RD & • & • & $\circ$ & $\bullet$ \\
\hline INF_RD & - & $\bullet$ & o & $\circ$ \\
\hline Raw Coverage & 0.291 & 0.293 & 0.381 & 0.324 \\
\hline Unique coverage & 0.083 & 0.086 & 0.174 & 0.117 \\
\hline Consistency & 0.817 & 0.874 & 0.885 & 0.881 \\
\hline Solution coverage & 0.377 & & 0.498 & \\
\hline Solution Consistency & 0.838 & & 0.901 & \\
\hline Frequency Cutoff & 1.000 & & 1.000 & \\
\hline Consistency Cutoff & 0.817 & & 0.881 & \\
\hline
\end{tabular}

Note: • indicates the presence of the condition (i.e., high level of support through this EFC); $\circ$ indicates the absence of the condition (i.e., low level of support through this EFC). The absence of dots indicates that there is neither a high or low level of support through that EFC.

Therefore, the values resulting from the calibration process constitute what will be considered in order to perform fsQCA. In particular, the fully in threshold indicated that any country above this value exhibited a high average impact score of small-size CBCs, whereas the fully out threshold indicated the absence of a high average impact score of small-size CBCs in the country and the maximum ambiguity indicated that it is not possible to determine the presence or absence of that outcome. In that sense, it is important to acknowledge that, of course, a bigger sample of countries may have led to different threshold levels. Therefore, we speak in terms of a high average impact score of small-size $\mathrm{CBC}$ in a country within the context of the analyzed countries.

\section{Results}

It must be noted that fsQCA allows for the realization of two analyses which offer different types of results or solutions [38]. First, the analysis of necessity, which aims to identify if the presence/absence of any of the studied causal conditions are necessary for the presence/absence of the outcome of interest. Secondly, the analysis of sufficiency, which aims to identify the combinations of the presence/absence of the causal conditions that are sufficient for the presence/absence of the outcome of interest. Given that our focus was on this second solution, and acknowledging the fact that, as stated by Ragin, it is extremely rare to find any necessary condition in complex social settings characterized by the conjoint influence of multiple factors (like the one of this study), we opted for only including the analysis of sufficiency results.

In any case, the analysis of necessity (which is automatically offered by the fsQCA software when performing the analysis) indicated, as expected, that neither the pres- 
ence/absence of any of the EFCs is necessary for the presence/absence of our outcome of interest.

In particular, we argue that this outcome is totally coherent with the multidimensional nature of impact and the high heterogeneity between countries at the economic and institutional level, which suggests that multiple combinations of the presence or absence of the EFCs will be needed for the presence or absence of high impact generation of small-size CBCs. In turn, this means that policymakers may have a higher degree of flexibility in terms of deciding which EFCs are used for promoting the generation of high impacts.

Considering the above, below we expose the resulting configurations from the sufficiency analysis.

Results of the Analysis of Sufficiency

The final step of the fsQCA was the evaluation of the validity of its solutions. This was done by using two indicators, consistency and coverage (both comprised in a range between 0 and 1). Consistency indicates, for the causal conditions individually, the degree of their relationship of necessity with the outcome, and for combinations of conditions, the degree of their relationship of sufficiency with the outcome [40]. Coverage, in turn, indicates the degree in which the solution explains the scores in every case of the sample, in a similar way to the percentage of variance explained in statistical methods.

In order for the solutions to be valid, every combination within them, and the solution overall, must have a minimum consistency value of 0.75 [38]. In this case, both models were valid given that all the configurations within them, and the models overall, had consistency values over that threshold (as shown in Table 5).

It must be noted that fsQCA allows the researchers to choose among three possible solutions: (a) the complex solution, which reduces the number of combinations by considering that those without cases do not produce an outcome; (b) the parsimonious solution, which minimizes the combinations by assuming that those without cases produce the outcome; and (c) the intermediate solution, which minimize combinations considering that only some of those without cases produce the outcome.

For our study, we chose to analyze the complex one because, in our view, the idea that a combination without cases does not produce any outcome was correct, given that in the considered reality, no one would be following this path and, therefore, there is no possibility of producing (or not) any outcome at all.

In particular, Model 1 showed those combinations of the presence/absence of the EFCs that are sufficient for the presence of a high average impact score of small-size CBCs in the country, whereas Model 2 indicated those combinations sufficient for the absence of this outcome.

Specifically, the configurations identified in both models and the countries that manifest them are as follows:

- Configuration 1a (Germany and Canada): a high level of support for SMEs in the form of financing for entrepreneurs, R\&D transfer and commercial and legal infrastructures was sufficient for the presence of a high average impact score of small-size CBCs in the country.

- Configuration 1b (Spain): a high level of support for SMEs in the form of taxes and bureaucracy, R\&D transfer and commercial and legal infrastructures was sufficient for the presence of a high average impact score of small-size CBCs in the country.

- Configuration 2a (United Kingdom and Chile): a low level of support for SMEs in the form R\&D transfer and commercial and legal infrastructures, together with a high level of support through taxes and bureaucracy, were sufficient for the absence of a high average impact score of small-size CBCs in the country.

- Configuration 2b (Italy): a low level of support for SMEs in the form of financing for entrepreneurs, taxes and bureaucracy and commercial and legal infrastructures, together with a high level of support through R\&D transfer, were sufficient for the absence of a high average impact score of small-size CBCs in the country. 
Given the above, in the next section we move to the detailed discussion of both models and the configurations within them.

\section{Discussion and Conclusions}

5.1. Comparative Discussion of Combinations Sufficient for the Presence $(1 a, 1 b)$ or the Absence $(2 a, 2 b)$ of a High Average Impact Score of Small-Size CBCs in the Country

First of all, combinations that are sufficient for the presence of a high average impact score of small-size CBCs in the country $(1 \mathrm{a}, 1 \mathrm{~b})$, highlight the relevance of R\&D transfer and commercial and legal infrastructures given their presence in both combinations.

Such relevance is also suggested by combinations in Model 2 given that in the first one (2a), the conjoint absence of R\&D transfer and commercial and legal infrastructures is sufficient for the absence of the outcome despite the presence of taxes and bureaucracy support and a middle level of financing for entrepreneurs.

The relevance of $R \& D$ transfer is also highlighted by combination $2 b$, in which its presence requires that the other three EFCs are absent in order to impede a high average impact score of small-size CBCs in the country, pointing to the importance of scientific knowledge for impact generation.

Nonetheless, such knowledge may be costly to obtain and to apply, pushing small and young firms to obtain it by cooperating with other organizations in order to reduce costs. This is particularly relevant for CBCs given that their dual mission and their aim of creating value for multiple stakeholders, may generate considerable tensions and trade-offs [5,7]. This may push them to cooperate with other organizations in order to overcome them.

Therefore, it is coherent that combinations $1 \mathrm{a}$ and $1 \mathrm{~b}$ exhibit both a high level of R\&D transfers and of commercial and legal infrastructures that support SMEs since R\&D transfer allows SMEs to obtain the most recent knowledge developments, and commercial and legal infrastructures to protect them in their interactions with other organizations. This may be crucial in order to promote the security of cooperation that may be developed in order to apply such knowledge.

In contrary, in combination $2 \mathrm{a}$, the absence of $\mathrm{R} \& \mathrm{D}$ implies that small-size CBCs are probably pushed to look for other, probably more costly, ways, to obtain and apply the scientific and technological knowledge that they need for innovating their business model, processes and/or products in order to remain competitive and generate impacts.

Nonetheless, those other ways, which usually imply the collaboration with other organizations, are also limited by the absence of commercial and legal infrastructures that support SMEs. This could lead to demotivating them to establish such cooperation and increase the transaction costs associated with them. In fact, in combination $2 \mathrm{a}$, where this absence is paired with that of $R \& D$ transfer, whereas in $2 b$, with that of financing for entrepreneurs and taxes and bureaucracy government policies that support them, that is the only EFC absent in the two combinations.

This points to the crucial relevance of cooperation and knowledge for the presence of a high average impact score of small-size CBCs in the country, because their absence is impeding it despite the presence of taxes and bureaucracy support and neither a high or low level of financing for entrepreneurs. In that sense, the absence in combinations 1a and $1 \mathrm{~b}$ of one of the EFCs more associated with the financial dimension, suggests their lower relevance coherent with the finding that financial systems have a less significant impact on firms' corporate social performance than other institutional systems [15]. Their presence/absence in the various combinations highlights the need to consider them and to look at EFCs and their influences in a systemic view.

In fact, presence in both combinations of either a high level of financing for entrepreneurs (1a) or a high level of taxes and bureaucracy (1b) that support SMEs, suggests that those efforts, either cooperative or individual, in order to exploit scientific knowledge, require a significant investment of resources, which in the case of small firms and especially CBCs (that many times reduce their margins at a minimum) may be difficult to assume.

Therefore, either support for SMEs in the form of financing for entrepreneurs or taxes and bureaucracy can facilitate the aforementioned exploitation of knowledge by helping 
firms to have the necessary resources they need in order to do so, either by increasing their access to external financing or by reducing taxes and bureaucracy burdens.

This reasoning is also suggested, but in an opposite sense, by combination $2 b$, since the high level of R\&D transfer requires the absence of the other three EFCs for impeding high impact generation at the national level. The reason behind that could be that despite being able to access recent scientific and technological advancements, the legal system is not protecting SMEs, thereby demotivating them to collaborate for understanding and exploiting that knowledge. Even more, the external environment is lacking from financial resources and is not reducing the burden of taxes and bureaucracy. The conjoint result of that is a significant limitation of the capacity of small-size CBCs to take advantage of the R\&D transfer because of the insecurity associated with commercial relationships, the burden of taxes and bureaucracy and scarcity of external financing.

In synthesis, first of all, the combinations highlight relevance of scientific knowledge for promoting impact generation, coherent with the previously found positive relationship between country technological and innovative capacities and CBCs impact [12]. This can be explained by the fact that scientific knowledge is crucial for entrepreneurs' innovations [32], with innovation in turn being a critical factor for the implementation, improvement and effectiveness of a sustainable business model that aims to generate positive impacts [41].

Secondly, combinations show that it is necessary to provide a secure infrastructure for SMEs in order to cooperate with other organizations and to also complement it with support from a financial or bureaucratic perspective, which is coherent with the finding that reducing entry- and growth-barriers are a way to improve entrepreneurship [9], potentially leading to positive effects in terms of innovative opportunities development [11]. In our context, this can be explained by the fact that impact generation of $\mathrm{CBCs}$ and the certification and re-certification process may require significant changes at multiple levels of the firm [7]. This implies a significant investment of resources that may lead to a deviation of commercial activities posing risks for profits and, therefore, for survival. Subsequently, the conjoint support resulting from the presence of $R \& D$ transfer, commercial and legal infrastructures and either financing for entrepreneurs or taxes and bureaucracy that support SMEs, may be crucial for promoting impact generation of small-size CBCs.

Finally, and in the opposite sense, the need to conjointly consider the various EFCs is also motivated by the potential barriers that may arise from their simultaneous absence or low level. In that sense, the absence of various EFCs in the solutions sufficient for the absence of a high level of average impact generation of small-size CBCs in the country, reveal the detrimental impacts that institutional voids can have on entrepreneurial ecosystems in general [42] and those that arise from the simultaneous absence of various $\mathrm{EFCs}$, coherently with the finding that institutional voids are a consequence of the absence or weakness of regulatory systems, contract-enforcement mechanisms and/or specialist intermediaries [42,43] (p. 62).

\subsection{Implications for Policymakers}

The complexity of the four combinations implies that policymakers have to jointly consider the EFCs that characterize the context in which entrepreneurs and SMEs operate. In that sense, findings suggest that it could be useful to simultaneously promote the access to scientific and technological advancements and commercial and legal infrastructures that support and protect SMEs in their interactions with other organizations.

Even more, given small-size firms' difficulties in terms of accessing financial resources and the reduced level of human resources they possess, it is relevant that the above support is paired with either a reduction of taxes and bureaucracy burden or a higher access to external financial resources in order to facilitate that R\&D transfer and the firm's cooperation can be exploited in a way that leads to improvements in competitiveness and impact generation.

Additionally, findings suggest that the barriers impeding the average impact generated by small-size CBCs in the country is a high result from the absence of various EFCs. This means that efforts directed toward reducing those barriers require the provision of supports through 
various EFCs. The reason for that is that this simultaneous absence, especially of R\&D transfer and commercial and legal infrastructures, produces restrictive complementarities that cannot be compensated with the support of just one EFC (i.e., taxes and bureaucracy in combination $2 \mathrm{a}$ and $R \& D$ transfer in $2 b)$.

5.3. Implications for Managers of Small-Size Firms That Aim to Generate Positive Impacts at the Social, Environmental and/or Governance Level

Managers could particularly benefit from an increased knowledge of the EFCs that characterize the national contexts in which they operate. From one side, the presence of various EFCs that support SMEs must be understood in order to use them for maintaining and improving competitiveness and high impact generation. Vice versa, their absence must also be considered-maybe even more-in order to identify ways to overcome institutional voids that make the achievement of the aforementioned goal difficult.

In both cases, we argue that CBCs may particularly benefit from joining the communities of $\mathrm{B}$ Corps at the international level, exchanging their knowledge regarding how $\mathrm{B}$ Corps, in general, and CBCs, in particular, adapt to institutional conditions depending on the impacts they aim to generate and the countries and economies in which they operate.

In that sense, combinations leading to the presence of high impacts highlight that a key factor for organizational learning and improvement is the collaboration with other organizations in order to jointly comprehend and exploit the last scientific and technological advances that may be available through a supporting R\&D transfer system.

In contrast, combinations leading to the absence of high impacts, in case where infrastructures, as well as R\&D transfer, are absent, CBCs could try to cooperate only with other CBCs. Given their social purpose and the ethical and moral values embedded in their business model [5], they may be more trustworthy, therefore helping to overcome the barriers for cooperation and development resulting from institutional voids.

Finally, when R\&D transfer is present, but the other EFCs are absent, we believe that it could still be adequate to take profit of the CBC communities, preferably those of firms within the same sector of activity and/or with similar organizational characteristics. Thus, co-creating ways to overcome institutional voids and obtain financing, for example, through the improvement of sustainable business models, of processes and/or of products and services which sell generate positive impacts by itself.

\subsection{Limitations, Suggestions for Future Research and Conclusion}

Our first limitation is the non-inclusion of other theoretically relevant EFCs. Therefore, future research could consider other EFCs in order to complement our findings, as well as those of previous studies that have paved the way toward understanding how institutional conditions influence entrepreneurial activities and outcomes (e.g., [10,32,44], as well as firms' positive contributions to society and the environment (e.g., [9,12,28]. In particular, we argue that those EFCs associated with the cultural-cognitive dimension (e.g., fear of failure, perceived skills for entrepreneurship) could be of special interest since they may be mediating, at the individual level, the effects of the other EFCs at the national level.

The second limitation of our study is the small size sample (17 countries). Nonetheless, both the GEM and the B Corp database provide data for many more countries. In conjunction with the fact that we have not been able to establish causality given the cross-sectional nature of our data, we suggest that a fruitful avenue for future research could be to study if there are differences in EFCs configurations that are sufficient for the presence/absence of a high average impact score of CBCs in the country depending on their size. In that sense, we think that it could be more useful to realize an analysis following previous works that aggregate EFCs in the three main institutional dimensions (regulatory, cultural-cognitive and normative).

Third, we have not considered the age of firms included in the sample. Therefore, it could be interesting to analyze if EFC combinations influencing CBCs impact scores change as a function of their age. Such work would be relevant for increasing our understanding regarding the differences in firms' outcomes depending on newness and smallness. It could 
also help to identify which combinations of policies may benefit small and mature firms and which ones could benefit those that are small and young.

Fourth, we have not considered other relevant factors at the organizational level that may explain the impact generation of firms (e.g., level of financial resources, economic performance, technological capabilities). Therefore, future works could look at if the configurations of EFCs that contribute to positive impacts of small firms are the same as those that contribute to their economic performance. In that sense, a comparison between CBCs and SMEs in terms of firm performance in relation to the EFCs would be valuable given the absence of such comparative research and the need to know more regarding the differences between CBCs and SMEs, which may be particularly relevant for stakeholders interested in them (e.g., investors).

Additionally, considering organizational characteristics as causal conditions in conjunction with various EFCs could reveal different combinations that may indicate the differing relevance of those factors in achieving a high impact score at the organizational and national levels.

Fifth, we have focused on how combinations of the presence/absence of EFCs promote or hinder a high average impact score of small-size CBCs in the country. Nonetheless, it could be that those EFCs differ from those that promote or hinder the diffusion of CBCs and firms aiming to generate positive impacts in countries. Therefore, future studies could analyze such combinations and look at if they differ from those found in this study.

Finally, we have focalized on a comprehensive measure of impact, but it could be that different EFCs and their combinations are promoting impact generation for different stakeholders. In that sense, the B Corp database allows for the analysis of specific impact dimensions because the global impact score for each firm is divided across the five pillars considered. Nonetheless, given the high variations that may exist, not only across sectors [45] but also within them [17,18], we argue that future research in this direction should preferably focus on analyzing a single sector or comparing two sectors that are significantly different. This is in order to better appreciate the differential influence of EFCs in the various impact dimensions depending on the sector to which the firms pertain.

In conclusion, our findings point to the increasing relevance of understanding those factors in order to inform policymakers about ways through which they can support those firms to increase their positive impacts. In that sense, the identified combinations reveal the crucial necessity of institutional supports in order to realize the complementarities between the private and the public sector and translate them in advancements toward a fairer world that recognizes the natural interdependency between all its agents and the subsequent necessity that we work together in order to promote well-being and sustainability.

Author Contributions: A.R. and J.A.V. contributed similarly to the development of the research and reports. All authors have read and agreed to the published version of the manuscript.

Funding: This research received no external funding.

Institutional Review Board Statement: Not applicable.

Informed Consent Statement: Not applicable.

Data Availability Statement: Both datasets used in this study are available online. Specifically, the most updated version of the B Corp database may be obtained at: https:/ / data.world/blab/bcorp-impact-data. For what regard Global Entrepreneurship Monitor data used for the considered entrepreneurial framework conditions, this is available at: https:/ /www.gemconsortium.org/data. Both datasets were accessed the 25 January 2021.

Acknowledgments: We would like to thank the two anonymous reviewers which suggestions helped us to significantly improve the quality and clarity of this study.

Conflicts of Interest: The authors declare no conflict of interest. 


\section{References}

1. George, G.; Howard-Grenville, J.; Joshi, A.; Tihanyi, L. Understanding and Tackling Societal Grand Challenges through Management Research. Acad. Manag. J. 2016, 59, 1880-1895. [CrossRef]

2. Howard-Grenville, J.; Davis, G.F.; Dyllick, T.; Miller, C.C.; Thau, S.; Tsui, A.S. Sustainable Development for a Better World: Contributions of Leadership, Management, and Organizations. Acad. Manag. Discov. 2019, 5, 355-366. [CrossRef]

3. Saiz-Alvarez, J.M.; Vega-Muñoz, A.; Acevedo-Duque, Á.; Castillo, D. B Corps: A Socioeconomic Approach for the COVID-19 Post-crisis. Front. Psychol. 2020, 11, 1867. [CrossRef] [PubMed]

4. ILO (International Labour Organization). COVID-19 and the World of Work: Impact and Policy Responses; ILO: Geneva, Switzerland, 2020.

5. Moroz, P.W.; Branzei, O.; Parker, S.C.; Gamble, E.N. Imprinting with purpose: Prosocial opportunities and B Corp certification. J. Bus. Ventur. 2018, 33, 117-129. [CrossRef]

6. Sarango-Lalangui, P.; Santos, J.L.S.; Hormiga, E. The Development of Sustainable Entrepreneurship Research Field. Sustainability 2018, 10, 2005. [CrossRef]

7. Stubbs, W. Sustainable Entrepreneurship and B Corps. Bus. Strat. Environ. 2017, 26, 331-344. [CrossRef]

8. Markman, G.D.; Waldron, T.L.; Gianiodis, P.T.; Espina, M.I. E Pluribus Unum: Impact Entrepreneurship as a Solution to Grand Challenges. Acad. Manag. Perspect. 2019, 33, 371-382. [CrossRef]

9. Urbano, D.; Alvarez, C. Institutional dimensions and entrepreneurial activity: An international study. Small Bus. Econ. 2014, 42, 703-716. [CrossRef]

10. Beynon, M.; Battisti, M.; Jones, P.; Pickernell, D. How Institutions Matter in the Context of Business Exit: A Country Comparison Using GEM Data and fsQCA. Br. J. Manag. 2020, 1-20. [CrossRef]

11. Arabiyat, T.S.; Mdanat, M.; Haffar, M.; Ghoneim, A.; Arabiyat, O. The influence of institutional and conductive aspects on entrepreneurial innovation: Evidence from GEM data. J. Enterp. Inf. Manag. 2019, 32, 366-389. [CrossRef]

12. Alonso-Martínez, D.; De Marchi, V.; Di Maria, E. Which country characteristics support corporate social performance? Sustain. Dev. 2019, 28, 670-684. [CrossRef]

13. Shepherd, D.A.; Wiklund, J. Simple Rules, Templates, and Heuristics! An Attempt to Deconstruct the Craft of Writing an Entrepreneurship Paper. Entrep. Theory Pract. 2019, 44, 371-390. [CrossRef]

14. Deng, W.; Liang, Q.Z.; Fan, P.H. Complements or substitutes? Configurational effects of entrepreneurial activities and institutional frameworks on social well-being. J. Bus. Res. 2019, 96, 194-205. [CrossRef]

15. Ioannou, I.; Serafeim, G. What drives corporate social performance? The role of nation-level institutions. J. Int. Bus. Stud. 2012, 43, 834-864. [CrossRef]

16. Ragin, C.C. Fuzzy-Set Social Science; University of Chicago Press: Chicago, IL, USA, 2000.

17. Lopez, B.; Torres, A.; Ruozzi, A.; Vicente, J.A. Main Factors for Understanding High Impacts on CSR Dimensions in the Finance Industry. Sustainability 2020, 12, 2395. [CrossRef]

18. Pascual, J.A.V.; Lopez, A.R.; Marín, A.J.T.; Vázquez, B.L. Multiple paths for being recognized as a high impact firm in the banking sector. Econ. Res. (Ekon. Istraživanja) 2021, 34, 2790-2811. [CrossRef]

19. Cao, K.; Gehman, J.; Grimes, M.G. Standing out and fitting in: Charting the emergence of Certified B Corporations by industry and region. In Hybrid Ventures; Emerald Publishing Limited: Somerville, MA, USA, 2017; pp. 1-38.

20. Sharma, G.; Beveridge, A.J.; Haigh, N. A configural framework of practice change for B corporations. J. Bus. Ventur. 2018, 33, 207-224. [CrossRef]

21. Moroz, P.W.; Gamble, E.N. Business model innovation as a window into adaptive tensions: Five paths on the B Corp journey. J. Bus. Res. 2021, 125, 672-683. [CrossRef]

22. Markman, G.D.; Russo, M.; Lumpkin, G.T.; Jennings, P.D.; Mair, J. Entrepreneurship as a Platform for Pursuing Multiple Goals: A Special Issue on Sustainability, Ethics, and Entrepreneurship. J. Manag. Stud. 2016, 53, 673-694. [CrossRef]

23. Belz, F.M.; Binder, J.K. Sustainable Entrepreneurship: A Convergent Process Model. Bus. Strat. Environ. 2017, 26, 1-17. [CrossRef]

24. Diez-Busto, E.; Sanchez-Ruiz, L.; Fernandez-Laviada, A. The B Corp Movement: A Systematic Literature Review. Sustainability 2021, 13, 2508. [CrossRef]

25. DiMaggio, P.J.; Powell, W.W. The Iron Cage Revisited: Institutional Isomorphism and Collective Rationality in Organizational Fields. Am. Sociol. Rev. 1983, 48, 147. [CrossRef]

26. Scott, W.R. Institutions and Organizations; Sage Publications: Thousand Oaks, CA, USA, 1995.

27. North, D.C. Institutions, Institutional Change and Economic Performance; Cambridge University Press: Cambridge, UK, 1990.

28. El Ghoul, S.; Guedhami, O.; Kim, Y. Country-level institutions, firm value, and the role of corporate social responsibility initiatives. J. Int. Bus. Stud. 2017, 48, 360-385. [CrossRef]

29. Hall, P.A.; Soskice, D. (Eds.) Varieties of Capitalism: The Institutional Foundations of Comparative Advantage; OUP Oxford: Oxford, UK, 2001.

30. Jackson, G.; Apostolakou, A. Corporate Social Responsibility in Western Europe: An Institutional Mirror or Substitute? J. Bus. Ethics 2010, 94, 371-394. [CrossRef]

31. Witt, M.A.; de Castro, L.R.K.; Amaeshi, K.; Mahroum, S.; Bohle, D.; Saez, L. Mapping the business systems of 61 major economies: A taxonomy and implications for varieties of capitalism and business systems research. Socio-Econ. Rev. 2017, 16, 5-38. [CrossRef]

32. Dilli, S.; Elert, N.; Herrmann, A.M. Varieties of entrepreneurship: Exploring the institutional foundations of different entrepreneurship types through 'Varieties-of-Capitalism' arguments. Small Bus. Econ. 2018, 51, 293-320. [CrossRef] 
33. Levie, J.; Autio, E. A theoretical grounding and test of the GEM model. Small Bus. Econ. 2008, 31, 235-263. [CrossRef]

34. Begley, T.M.; Tan, W.-L.; Schoch, H. Politico-Economic Factors Associated with Interest in Starting a Business: A Multi-Country Study. Entrep. Theory Pract. 2005, 29, 35-55. [CrossRef]

35. Van Stel, A.; Storey, D.J.; Thurik, A.R. The Effect of Business Regulations on Nascent and Young Business Entrepreneurship. Small Bus. Econ. 2007, 28, 171-186. [CrossRef]

36. Van De Ven, H. The development of an infrastructure for entrepreneurship. J. Bus. Ventur. 1993, 8, 211-230. [CrossRef]

37. Ragin, C.C. The Comparative Method: Moving Beyond Qualitative and Quantitative Strategies; University of California Press: Berkeley, CA, USA, 1987.

38. Ragin, C.C. Measurement versus calibration: A set-theoretic approach. In The Oxford Handbook of Political Methodology; Oxford University Press (OUP): Oxford, UK, 2008.

39. Fainshmidt, S.; Witt, M.A.; Aguilera, R.V.; Verbeke, A. The contributions of qualitative comparative analysis (QCA) to international business research. J. Int. Bus. Stud. 2020, 51, 455-466. [CrossRef]

40. Legewie, N. An introduction to applied data analysis with qualitative comparative analysis. Forum Qual. Soz./Forum Qual. Soc. Res. 2013, 14. [CrossRef]

41. Schaltegger, S.; Lüdeke-Freund, F.; Hansen, E.G. Business Models for Sustainability: A co-evolutionary analysis of sustainable entrepreneurship, innovation, and transformation. Organ. Environ. 2016, 29, 264-289. [CrossRef]

42. Cao, Z.; Shi, X. A systematic literature review of entrepreneurial ecosystems in advanced and emerging economies. Small Bus. Econ. 2021, 57, 75-110. [CrossRef]

43. Khanna, T.; Palepu, K.G. Emerging Giants: Building World-Class Companies in Developing Countries. Harv. Bus. Rev. 2006, 10. Available online: https://hbr.org/2006/10/emerging-giants-building-world-class-companies-in-developing-countries (accessed on 4 April 2021).

44. Busenitz, L.W.; Gómez, C.; Spencer, J.W. Country Institutional Profiles: Unlocking Entrepreneurial Phenomena. Acad. Manag. J. 2000, 43, 994-1003. [CrossRef]

45. Orlitzky, M.; Louche, C.; Gond, J.-P.; Chapple, W. Unpacking the Drivers of Corporate Social Performance: A Multilevel, Multistakeholder, and Multimethod Analysis. J. Bus. Ethics 2017, 144, 21-40. [CrossRef] 